\title{
PYROTECHNICAL SURVEY IN DUKLA PASS REGION (NE SLOVAKIA)
}

\author{
Jozef Hricko ${ }^{1}$ and Ján Tkác ${ }^{1}$ \\ 1 Geocomplex a. s., Geologická 21, 82207 Bratislava, Slovak Republic
}

\begin{abstract}
The detecting and liquidation of ammunition in the World.War II. battles areas is an important task of engineering geophysics in Slovakia. The paper presented deals with a results of pyrotechnical survey in Dukla pass area (north-eastern Slovakia). In this region, one of the most horrible battle took place at the end of World War II. between German and Soviet-Czechoslovak troops.
\end{abstract}

The pyrotechnical survey has been a part of project for the construction of international high voltage electric line. The micromagnetic survey has been a dominant technique utilizing the fact that ammunition of this era mainly consisted of ferromagnetic material as iron, steel and their various alloys. This ammunition possesses its dangerous properties for inhabitants still, after more than $\mathbf{5 0}$ years from the Dukla pass battle.

The local magnetic anomalies, caused by the ammunition, have been detected by precise ground magnetometry. The geological sources of anomalies do not exist in the area of interest as the region is built by Paleogene flysch sediments (sandstones, mudstones, siltstones). The depth penetration required - 3 metres - has been easily reached.

After interpretation of magnetic anomalies, which resulted to determination of spacial extent, shape and depth of disturbing body, the replacement of overburden has been carried out. During this activity, the detector of metals was permanently used.

During first phase of a/m survey, performed during end of 1996 year, about $40 \mathrm{pcs}$ of various ammunition was detected and liquidated in the area in question. The survey continues in this year.

The pyrotechnical survey in Dukla pass region has been performed by Geocomplex a. s. Company for ENERGOMETAL Ltd.

\section{- INTRODUCTION}

The geophysical techniques have wide use in site assessment for various purposes. In Slovakia, an assessment of areas of World War II. battles from ammunition presence viewpoint is a frequent task of many projects. 
This paper deals with results of pyrotechnical survey, carried out in Dukla pass region (NE Slovakia-See Fig. 1). In this region, the bloody battle took place at the end of World War II. between German and Soviet-Czechoslovak troops. The 77,000 of Soviet and 6,000 of Czechoslovak soldiers as well as several thousands of German soldiers died there.

The pyrotechnical survey is a part of the project for construction of high voltage electric line running from Slovakia to Poland. The micromagnetic survey has been used for detection of active ammunition (bombs, mines, grenades, cartridges, etc.). Besides ground magnetometry, a detector of metals was used.

\section{METHODOLOGY AND RESULTS}

The ground magnetic survey has been located along planned electric line. The observations have been caried out in network of $1.0 \times 1.0 \mathrm{~m}$ around future pole at the square of 70.0 by $70.0 \mathrm{~m}$. A combination of two PM-2 proton magnetometers has been used, to observe both T-component of geomagnetic field and its vertical gradient. The proton probes have been located on one pole, the high of lower probe above surface was $0.50 \mathrm{~m}$, the distance between probes $-1.0 \mathrm{~m}$. The values measured have been stored on magnetic tape.

The anomalies detected by magnetometry have been verified by detector of metals (DISCOVERER TM-91). The detected and verified metallic bodies have been immediately stripped by hand digging. The ammunition found out has been liquidated by professional pyrotechnician.

During a 1996 year phase of survey, about fourty pcs of various active ammunition was detected and liquidated in the Dukla pass area.

The part of $T$ graphs and example of the magnetic modelling are shown in Fig. 2.

\section{CONCLUSIONS}

The pyrotechnical survey at the place of bloody World War II. battle - in Dukla pass region - has brought very useful information. By precise magnetometry, using detector of metals, many active ammunition have been discovered.

It facilitates the safety construction of the important international high voltage electric line in this area. 


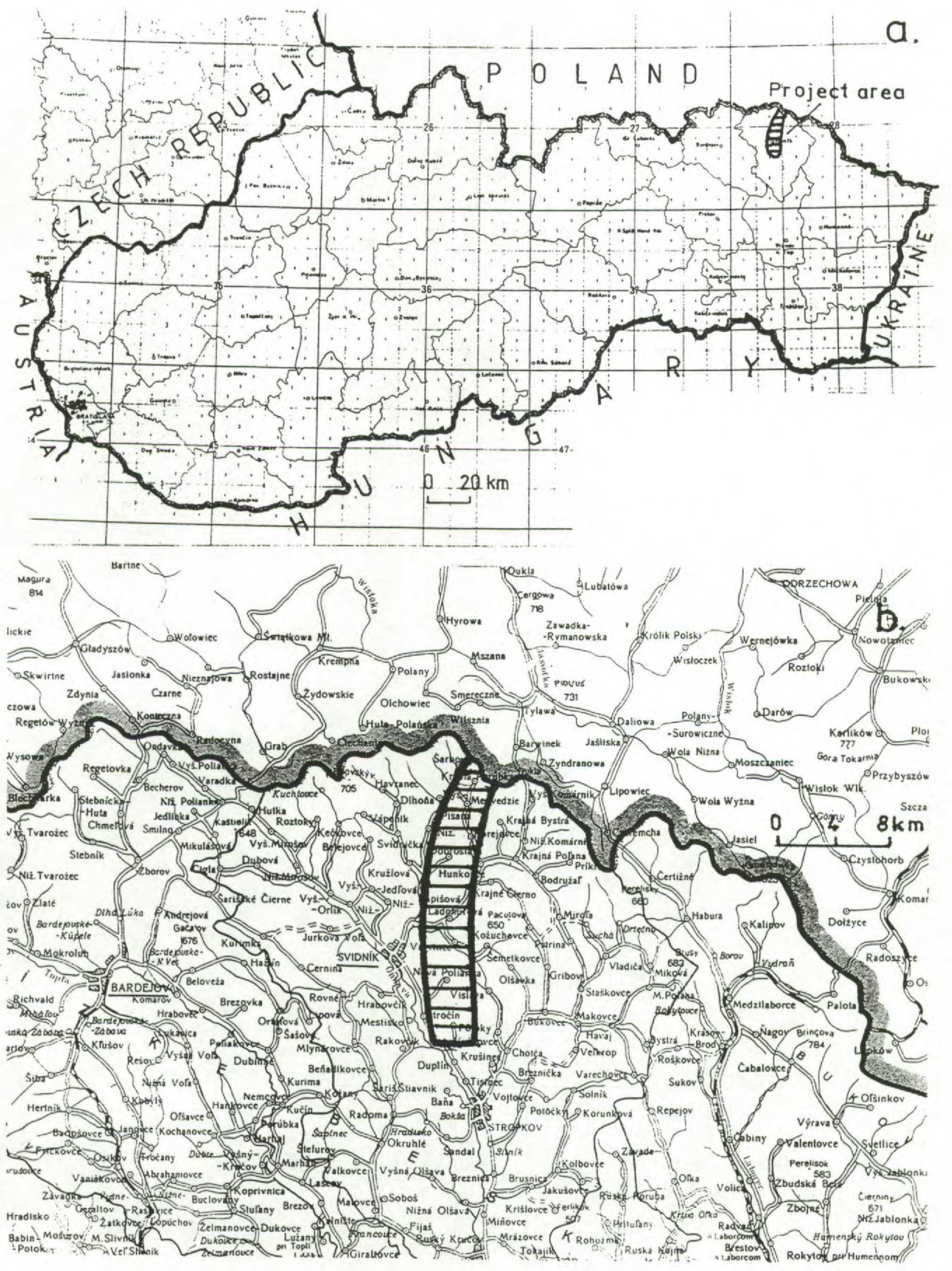

Fig. 1. Location of the project area (a. within Slovak territory, b. in north-eastern part of Slovakia) 

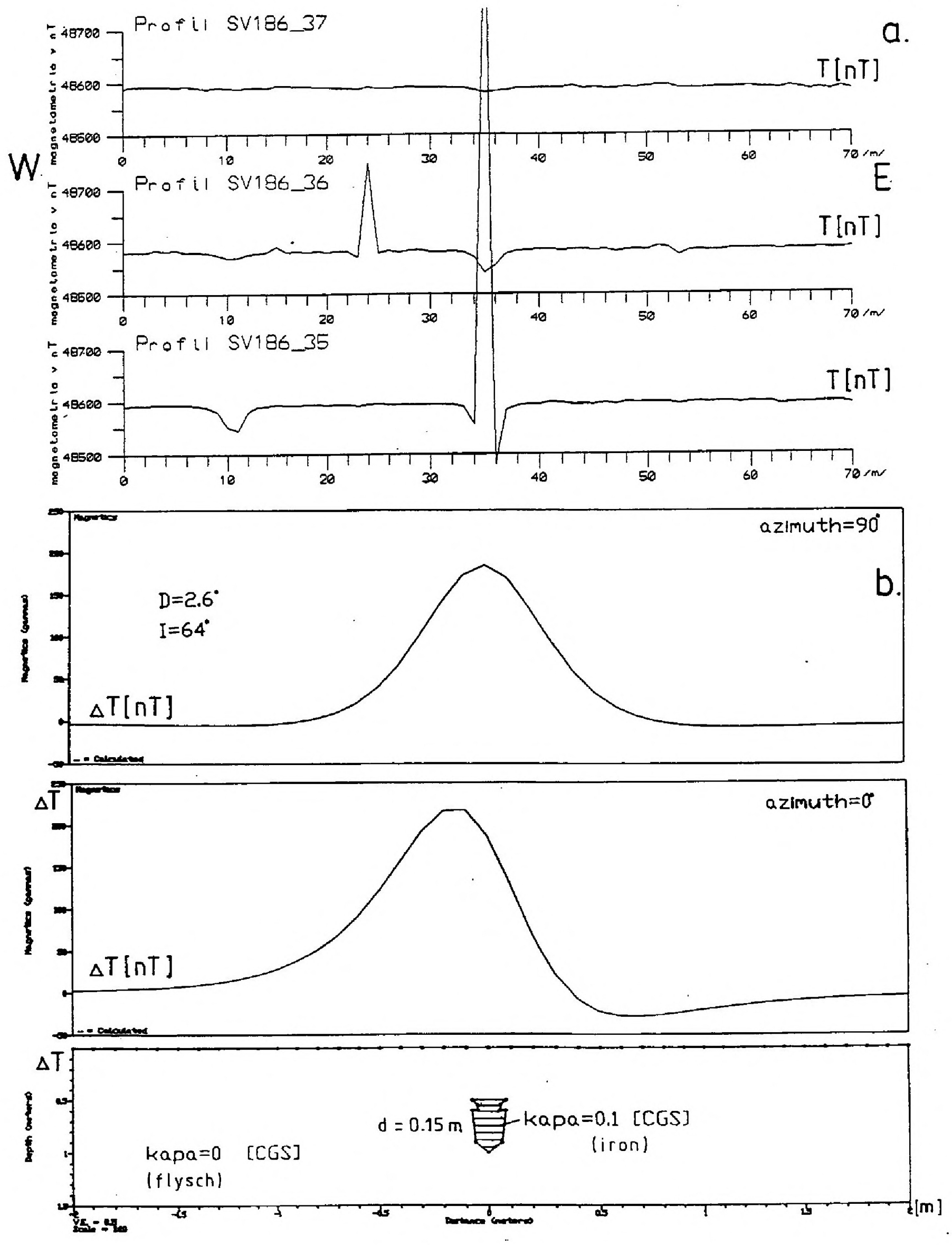

Fig. 2. T graphs (a.) and magnetic modelling above air bomb (b.) 